\title{
Diversity in Dermatology Clinical Trials
}

\section{Citation}

Charrow, Alexandra, Fan Di Xia, Cara Joyce, and Arash Mostaghimi. 2017. “Diversity in Dermatology Clinical Trials." JAMA Dermatology 153 (2) (February 1): 193. doi:10.1001/ jamadermatol.2016.4129.

\section{Published Version}

doi:10.1001/jamadermatol.2016.4129

\section{Permanent link}

http://nrs.harvard.edu/urn-3:HUL.InstRepos:33785927

\section{Terms of Use}

This article was downloaded from Harvard University's DASH repository, and is made available under the terms and conditions applicable to Other Posted Material, as set forth at http:// nrs.harvard.edu/urn-3:HUL.InstRepos:dash.current.terms-of-use\#LAA

\section{Share Your Story}

The Harvard community has made this article openly available.

Please share how this access benefits you. Submit a story.

Accessibility 
IMPORTANCE Though there have been significant shifts in US demographic data over the past 50 years, research cohorts lack full racial and ethnic representation. There is little data available regarding the diversity of dermatology research cohorts with respect to sex, race, and ethnicity.

OBJECTIVE To characterize and assess the representation of racial and ethnic minorities and women in randomized controlled trials across a range of dermatologic conditions.

EVIDENCE REVIEW All randomized clinical trials (RCTs) were identified between July 2010 and July 2015 within the PubMed database using the following keywords: "psoriasis," "atopic dermatitis," "acne," "vitiligo," "seborrheic dermatitis," "alopecia areata," and "lichen planus." Diverse study populations were defined as including a greater than $20 \%$ racial or ethnic minority participants based on US census data. The distributions of sex and race groups in studies were compared by journal type, disease type, and funding source.

FINDINGS Of the 626 articles reporting RCTs included in this analysis, 532 (85.0\%) reported the sex of study participants. Overall, 52 of 626 international (11.3\%) studies and 58 of 97 studies (59.8\%) conducted exclusively within the United States reported on the racial or ethnic demographics of study participants. Across all RCTs exclusively recruited within the United States that reported race, $74.4 \%$ of study participants were white. Disease type was significantly associated with the degree of racial diversity $(P<.001)$ within a study cohort: $30.0 \%$ of US-based psoriasis had more than $20 \%$ racially or ethnically diverse research participants as compared with $73.9 \%$ of acne studies and $91.7 \%$ of eczema studies.

CONCLUSION AND RELEVANCE Dermatologic clinical trials within the United States reflect the growing diversity of the US population. Reporting of both sex and racial/ethnic diversity of research cohorts is still lacking, especially among studies conducted outside of the United States.

JAMA Dermatol. 2017;153(2):193-198. doi:10.1001/jamadermatol.2016.4129 Published online January 4, 2017.
Editorial page 132

Author Audio Interview

Author Affiliations: Harvard Combined Dermatology Residency Training Program, Harvard Medical School, Boston, Massachusetts (Charrow); Brigham \& Women's Hospital, Harvard Medical School, Boston, Massachusetts (Xia): Walgreen Co, Deerfield, Illinois (Joyce); Department of Dermatology, Brigham \& Women's Hospital, Harvard Medical School, Boston, Massachusetts (Mostaghimi).

Corresponding Author: Arash Mostaghimi, MD, MPA, MPH, Instructor in Dermatology and Internal Medicine, Harvard Medical School, Brigham and Women's Hospital, 75 Francis St, PBB-B 421, Boston, MA 02115 (amostaghimi @bwh.harvard.edu).
$\mathrm{T}$ he growth of the minority population in the United States is outpacing the growth of the non-Hispanic white population. Current projections estimate that the United States will achieve "majority-minority" status in which minority populations total over $50 \%$ of the overall population by $2044{ }^{1}$

This demographic shift has not been reflected in medical research. African Americans, Hispanic individuals, and women are underrepresented in clinical ${ }^{2}$ and randomized controlled trials generally, ${ }^{3}$ as well as within specific subspecialties including cancer clinical trials, ${ }^{4}$ pulmonary research, ${ }^{5}$ vascular surgery trials, ${ }^{6}$ and orthopedic research. ${ }^{7}$ General reporting of the racial and ethnic demographics of study cohorts is uncommon as well, with less than one-third of papers published in high-impact journals across all fields reporting racial or ethnic demographics. ${ }^{8}$

Federal efforts have targeted inclusion of clinical trial and research subjects at levels proportionate with those in the US population. ${ }^{9}$ The US Food and Drug Administration (FDA) currently requires that all investigational new drug and new drug applications studies include demographic information prior to approval. ${ }^{10}$ Additionally, National Institutes of Health $(\mathrm{NIH})$ funded clinical research studies must include women and minorities. ${ }^{11}$

Despite a call to action to achieve diversity in research, that we know of there has been no systematic evaluation of clinical and research diversity among dermatology research subjects to date. Hirano et al ${ }^{12}$ examined racial representation in atopic dermatitis research, demonstrating that only $60 \%$ of clinical trials of eczema and/or atopic dermatitis reported race.

This systematic review of the dermatology literature analyzed the degree of racial, ethnic, and sex representation in recent randomized clinical trials (RCTs) for acne, psoriasis, atopic dermatitis and eczema, vitiligo, alopecia areata, seborrheic dermatitis, and lichen planus (LP). These conditions were selected because they are: 
(1) common, (2) lack specific racial predilection, and (3) wellstudied. Nonmelanoma skin cancer, melanoma studies were not included in this review because of their disproportionate occurrence in white patients. ${ }^{13}$ Dyschromia and melasma were not included because of their disproportionate occurrence in patients with skin of color.

\section{Methods}

\section{Search Strategy}

A comprehensive systematic review of the literature was performed using the electronic database PubMed from the 5-year period between July 21, 2010, and July 21, 2015, for all peer-reviewed, English-language RCTs pertaining to acne, psoriasis, atopic dermatitis and eczema, vitiligo, lichen planus, alopecia areata, and seborrheic dermatitis. Search criteria were defined to include studies with the following key words: "lichen planus," "psoriasis," "atopic dermatitis," "eczema," "acne," "seborrheic dermatitis," "alopecia areata," and "vitiligo" in the title, abstract, or body of potential search results. The titles and abstracts were reviewed prior to data abstraction; animal studies and studies of nondermatologic conditions were excluded. All data was obtained from publically available sources; institutional review board review was waived.

\section{Race and Ethnicity Categorization}

Race and ethnicity categorizations were defined using the constructs outlined by the Office of Management and Budget guidelines for federal data: American Indian or Alaskan Native, Asian, black or African American, Native Hawaiian or Other Pacific Islander, and white. Hispanic identity was recorded as a racial category in some articles and as an ethnicity in others. To reconcile this discrepancy, we recorded all participants who indicated they were of either of Hispanic ethnicity or Hispanic race as "Hispanic." Individuals who indicated that they were any race other than white were considered nonwhite for bivariate analysis.

\section{Data Abstraction}

Each article title and abstract were reviewed and nondermatologic and animal-model papers were eliminated. The full text of all remaining articles was reviewed. Study data were collected and managed using REDCap (Research Electronic Data Capture) electronic data capture tools hosted through Partners Healthcare. ${ }^{14}$ Data was abstracted across the following domains: reporting of participant Fitzpatrick skin type, reporting of participant race, reporting of participant sex, and participant counts by sex and racial and/or ethnic demographic information. Any mention of demographic sex, race, and ethnicity was considered to be a report of such data, regardless of whether the data was reported in a study-subject table or the body of the paper.

We extracted year of publication, disease of concern, total number of patients, funding type (industry, foundation/nonprofit, government, none, or nonlisted), journal name, and journal type. Multiple papers from the same study or patient cohort were considered independently. The top $20 \%$ of articles (consisting of approximately $80 \%$ of the patients in this analysis) were independently validated by a second data abstractor to ensure accuracy and consistency.

\section{Key Points}

Question What is the racial, ethnic, and sex makeup of participants in randomized clinical trials of dermatologic conditions?

Findings In this systematic review of 626 trials conducted in 2010 through 2015, there was a low level of reporting of racial and ethnic composition of trial participants. Those US trials that reported race and ethnicity included a proportional number of women and African Americans compared with the general population, but Hispanic representation was lower than that of the general population of the United States.

Meaning While dermatologic clinical trials conducted in the United States are racially diverse, the field must increase reporting of race and ethnicity and strive for representative study cohorts especially with respect to ethnic diversity.

\section{Statistical Analysis}

Characteristics of included studies were presented as counts and percentages. Studies that reported race, ethnicity, and sex were categorized by their study participant distributions compared to the US population. We considered studies with less than $20 \%$ ethnically or racially diverse participants (defined as nonwhite race or Hispanic ethnicity) or less than $45 \%$ women to be underrepresentative of race/ ethnicity, and sex, respectively. Counts and percentages of funding source, journal type, and disease type were presented overall and by level of race and ethnicity, and sex representation. The statistical significance of study differences by race and ethnicity, and sex representation was determined by $\chi^{2}$ tests or Fisher exact tests as appropriate. Analyses were performed using SAS 9.4 (SAS Institute).

\section{Results}

A total of 991 unique articles were identified. After elimination of 257 articles concerning nondermatologic conditions or conducted in nonhuman patients, elimination of duplicate articles $(n=10)$, nonRCTs $(n=89)$, and articles on diseases not included in our study $(n=9), 626$ articles were ultimately included in the analysis. Of these, 97 studies were exclusively conducted in the United States and 164 were partially conducted in the United States (Figure 1).

\section{Reporting of Race and Ethnicity}

Race and ethnicity demographic data were included across at least 1 variable in 58 of 97 studies (59.8\%) conducted exclusively in the United States and 97 of 164 studies (59.1\%) conducted exclusively or partially in the United States (Figure 1); 52 of 462 studies (11.3\%) that recruited outside of the United States recorded race or ethnicity. Information regarding whether race was self-reported was not reported in the vast majority of studies; a subanalysis of 53 studies revealed only $3(5.7 \%)$ with reported data, all 3 of which were selfreported. Of the 58 studies recruited exclusively within the United States that reported data on race or ethnicity, 20 investigated psoriasis; 12 , atopic dermatitis; 23 , acne; 2 , vitiligo; and 1, seborrheic dermatitis for a total of 13681 study participants. None of the articles about lichen planus ( $\mathrm{n}=2$ in United States) or alopecia areata ( $\mathrm{n}=1$ in the United States) reported race or ethnicity. 
Funding source, journal type, and disease type were associated with the reporting of racial and ethnic data $(P<.001$ for all comparisons; Table 1). Articles containing research funded by industry ( $n=116$ [42.3\%]) were more likely to report race and ethnicity than research funded by other entities ( $P<.001$ for all comparisons). Studies in dermatology pharmacology journals ( $n=29$ [50.9\%]) were most likely to report race and ethnicity $(P<.001)$.

A subgroup analysis of trials conducted exclusively in the United States ( $n=97$ ) demonstrated a correlation between disease type and reporting of race/ethnicity, with vitiligo $(n=2[100 \%])$ and psoriasis ( $n=20[76.9 \%])$ studies more likely to report than acne $(n=23$ [54.8\%]) and eczema $(n=12[52.5 \%])(P<.001$ for all comparisons).

\section{Racial Composition of Trials}

Overall, among the 58 studies conducted exclusively within the United States that recorded race/ethnicity, 10177 of 13681 (74.4\%) study participants were white. Among these studies, 46 (79.3\%) noted racial categories other than white and nonwhite for a total of 11140 participants; of these, 8016 (72.0\%) of study participants were white, 1446 (13.0\%) were African American, 1639 (14.7\%) were recorded as Hispanic, and 370 (3.3\%) were recorded as Asian; 331 of these 11140 participants identified themselves as ethnically Hispanic and racially as nonwhite and were thus counted within the totals of both groups. Articles about eczema ( $n=11$ [91.7\%]) and acne studies ( $n=17$ [73.9\%]) were more likely to include more than $20 \%$ racially/ethnically diverse participants than psoriasis studies $(P<.001)$ (Table1). Psoriasis studies included the least diversity with $84.3 \%$ of total study participants recorded as white. Funding source and journal type did not demonstrate a statistically significant relationship with respect to the diversity of study subjects $(P=.70$ and $P=.21$, respectively [Table 1$]$ ).

\section{Reporting and Distribution of Sex}

A total of 532 articles (85.0\%) included data on the number of male and women participants. The majority of participants (68 760 of 125266 [54.9\%]) were women. General medicine ( $n=20$ [87.0\%]) and dermatology journals ( $n=346$ [87.2\%]) were more likely to report sex distribution than other journal types $(P=.03)$ (Table 2$)$.

Disease type, funding source, and journal type all demonstrated a statistically significant relationship to the proportion of women participants within a given study ( $P \leq .01$ across all comparisons; Figure 2). Articles funded by industry ( $n=175$ [75.1\%]) were more likely to have more than $45 \%$ women when compared with those supported by other sources $(P<.001)$. Psoriasis studies were overrepresentative of women, as $87.2 \%$ of reporting studies had greater than $45 \%$ women, and 42190 of 65984 participants (63.9\%) were women (Table 2).

\section{Discussion}

Our analysis of randomized clinical trials in dermatology in acne, vitiligo, and atopic dermatitis over the past 5 years demonstrates a diverse racial and ethnic representation and roughly equal representation of sex. This contrasts with other medical specialties where full racial representation lags. ${ }^{15,16}$ However, representation of Hispanics and other minorities were still somewhat lacking. While those trials that fully characterized race achieved recruitment of a proportional

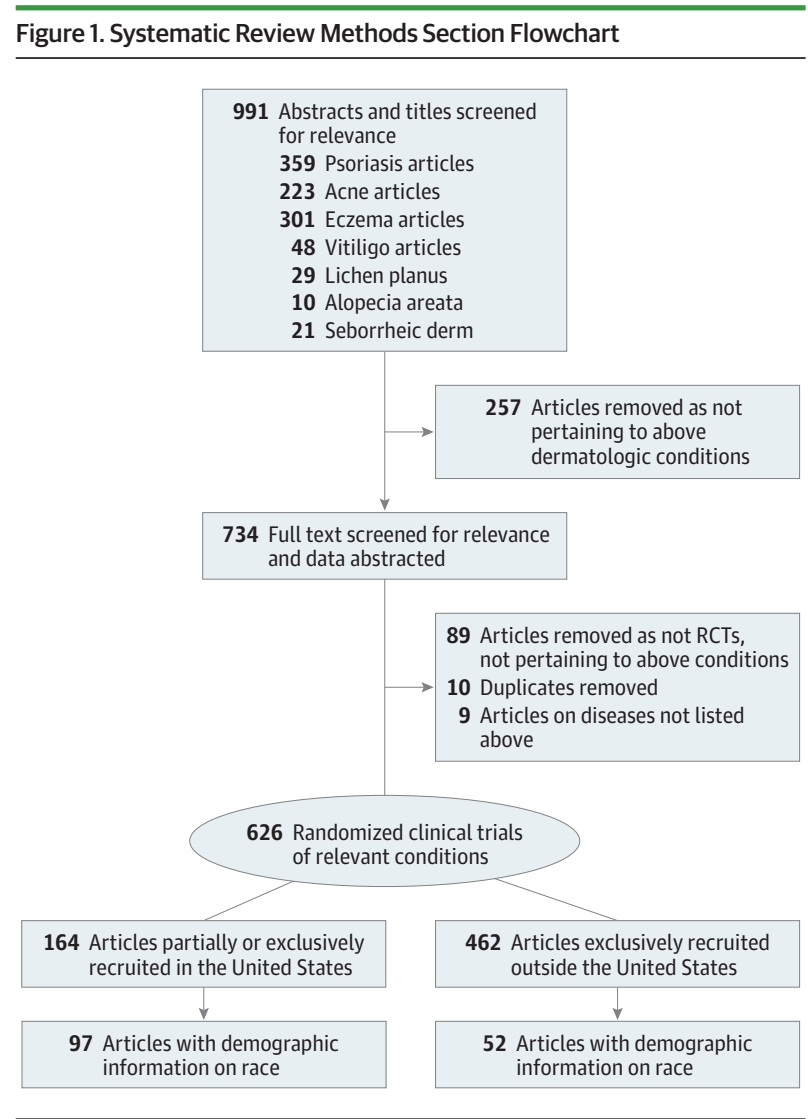

This figure demonstrates the process by which articles were eliminated from review.

number of African American participants (compared with the US population at 13\%), those same trials did not achieve such proportionality with respect to ethnicity. Although $17 \%$ of the population identifies as Hispanic by ethnicity, only $14.7 \%$ of participants in those same studies identified ethnically as Hispanic. Moreover, the dearth of full reporting of ethnicity and race suggests that the actual racial and ethnic makeup of many studies may be decidedly more homogenous.

Dermatologic research seems to be achieving racial diversity in most clinical trials where such data are reported, but the low rate of full reporting and the lower-than-proportional representation of Hispanic individuals requires greater attention. Significant health disparities exist between whites and racial/ethnic minorities. ${ }^{17} \mathrm{Di}$ verse research cohorts are needed to demonstrate the potential disparities in treatment of dermatologic diseases, and investigate effective treatments. Assuring this racial/ethnic and sex diversity will help advance clinical medicine while promoting patient equity. To that end, dermatology trials need to improve their reporting of demographic data. Only $59.8 \%$ of papers conducted exclusively within the United States reported the racial demographics of their study participants despite the ease with which such data can be collected and reported. Although low, the US reporting is substantially higher than reporting among non-US studies (11.3\% reporting of race or ethnicity). This may represent unique demographic differences between the United States and Europe or the influence of targeted diversity policy on research in the United States including the National Institutes of Health (NIH) Revitalization Act of $1993^{18}$ and additional guidelines put in place by $\mathrm{NIH}$ in $2000 .^{19}$ 


\begin{tabular}{|c|c|c|c|c|c|c|c|c|}
\hline Publication Characteristics & $\begin{array}{l}\text { No. of } \\
\text { All RCTs }\end{array}$ & $\begin{array}{l}\text { RCT Reported } \\
\text { Race/Ethnicity, } \\
\text { No. (\%) }\end{array}$ & $P$ Value $^{\mathrm{a}}$ & $\begin{array}{l}\text { Exclusively } \\
\text { US RCTs, No. }\end{array}$ & $\begin{array}{l}\text { RCT Reported } \\
\text { Race/Ethnicity, } \\
\text { No. (\%) }\end{array}$ & $P$ Value $^{\mathrm{a}}$ & $\begin{array}{l}\geq 20 \% \text { Nonwhite } \\
\text { Representation, } \\
\text { No. }(\%)^{\mathrm{b}}\end{array}$ & $P$ Value $^{\mathrm{a}}$ \\
\hline Overall & 626 & $149(23.8)$ & & 97 & $58(59.8)$ & & $37(63.8)$ & \\
\hline Funding & & & $<.001$ & & & .03 & & .70 \\
\hline Government & 48 & $7(14.6)$ & & 5 & $5(100)$ & & $4(80.0)$ & \\
\hline Industry & 274 & $116(42.3)$ & & 66 & $41(62.1)$ & & $24(58.5)$ & \\
\hline Government/industry mix & 8 & $1(12.5)$ & & 0 & NA & & NA & \\
\hline Nonprofit & 64 & 7 (10.9) & & 9 & $2(22.2)$ & & $2(100)$ & \\
\hline No funding & 43 & 0 & & 1 & 0 & & NA & \\
\hline Funding not specified & 189 & $18(9.5)$ & & 16 & $10(62.5)$ & & $7(70.0)$ & \\
\hline Disease type & & & $<.001$ & & & .06 & & .001 \\
\hline Psoriasis & 216 & $77(35.6)$ & & 26 & 20 (76.9) & & $6(30.0)$ & \\
\hline Eczema & 181 & $28(15.5)$ & & 23 & $12(52.2)$ & & $11(91.7)$ & \\
\hline Acne & 144 & $35(24.3)$ & & 42 & $23(54.8)$ & & 17 (73.9) & \\
\hline Lichen planus & 25 & $1(4.0)$ & & 2 & 0 & & NA & \\
\hline Vitiligo & 36 & $4(11.1)$ & & 2 & $2(100)$ & & $2(100)$ & \\
\hline Alopecia areata & 8 & 0 & & 1 & 0 & & NA & \\
\hline Seborrheic dermatitis & 16 & $4(25.0)$ & & 1 & $1(100)$ & & $1(100)$ & \\
\hline Journal type & & & $<.001$ & & & .62 & & .21 \\
\hline Dermatology & 397 & $93(23.4)$ & & 53 & $33(62.3)$ & & $22(66.7)$ & \\
\hline General medicine & 23 & $6(26.1)$ & & 0 & NA & & NA & \\
\hline Dermatology pharmacology & 57 & $29(50.9)$ & & 33 & $18(54.5)$ & & $13(72.2)$ & \\
\hline General pharmacology & 13 & $2(15.4)$ & & 1 & $1(100)$ & & 0 & \\
\hline Allergy & 45 & $6(13.3)$ & & 5 & $2(40.0)$ & & $1(50.0)$ & \\
\hline Other/undetermined & 91 & $13(14.3)$ & & 5 & $4(80.0)$ & & $1(25.0)$ & \\
\hline
\end{tabular}

Abbreviations: NA, not applicable; RCT, randomized clinical trial.

a $P$ values from $\chi^{2}$ or Fisher exact tests as appropriate.

${ }^{\mathrm{b}}$ The percent is calculated among studies conducted exclusively in the US that report race.

\begin{tabular}{|c|c|c|c|c|c|}
\hline Publication Characteristics & $\begin{array}{l}\text { No. of } \\
\text { All RCTs }\end{array}$ & $\begin{array}{l}\text { RCT } \\
\text { Reported Sex, } \\
\text { No. (\%) }\end{array}$ & $P$ Value $^{\mathrm{a}}$ & $\begin{array}{l}\geq 45 \% \text { Women } \\
\text { Representation, } \\
\text { No. }(\%)^{b}\end{array}$ & $P$ Value $^{\mathrm{a}}$ \\
\hline Overall & 626 & $532(85.0)$ & & $349(65.6)$ & \\
\hline Funding & & & .65 & & $<.001$ \\
\hline Government & 48 & $38(79.2)$ & & $21(55.3)$ & \\
\hline Industry & 274 & $233(85.0)$ & & $175(75.1)$ & \\
\hline Government/industry mix & 8 & $6(75.0)$ & & $4(66.7)$ & \\
\hline Nonprofit & 64 & $56(87.5)$ & & $28(50.0)$ & \\
\hline No funding & 43 & $39(90.7)$ & & $28(71.8)$ & \\
\hline Funding not specified & 189 & $160(84.7)$ & & $93(58.1)$ & \\
\hline Disease type & & & .27 & & $<.001$ \\
\hline Psoriasis & 216 & $188(87.0)$ & & $164(87.2)$ & \\
\hline Eczema & 181 & $147(81.2)$ & & $102(69.4)$ & \\
\hline Acne & 144 & $124(86.1)$ & & $51(41.1)$ & \\
\hline Lichen planus & 25 & $19(76.0)$ & & $5(26.3)$ & \\
\hline Vitiligo & 36 & $31(86.1)$ & & $12(38.7)$ & \\
\hline Alopecia areata & 8 & $7(87.5)$ & & $4(57.1)$ & \\
\hline Seborrheic dermatitis & 16 & $16(100)$ & & $11(68.8)$ & \\
\hline Journal type & & & .03 & & .004 \\
\hline Dermatology & 397 & $346(87.2)$ & & $219(63.3)$ & \\
\hline General medicine & 23 & $20(87.0)$ & & $16(80.0)$ & \\
\hline Dermatology pharma & 57 & 41 (71.9) & & $28(68.3)$ & \\
\hline General pharmacology & 13 & $9(69.2)$ & & $9(100)$ & \\
\hline Allergy & 45 & $37(82.2)$ & & $32(86.5)$ & \\
\hline Other/undetermined & 91 & $79(86.8)$ & & $45(57.0)$ & \\
\hline
\end{tabular}

Abbreviation: RCT, randomized clinical trial.

a $P$ values from Fisher exact tests.

${ }^{\mathrm{b}}$ The percent is calculated among studies that report sex. 
Figure 2. Demographic Composition of Dermatologic Studies Conducted Within the United States Reporting Both Race/Ethnicity and Sex

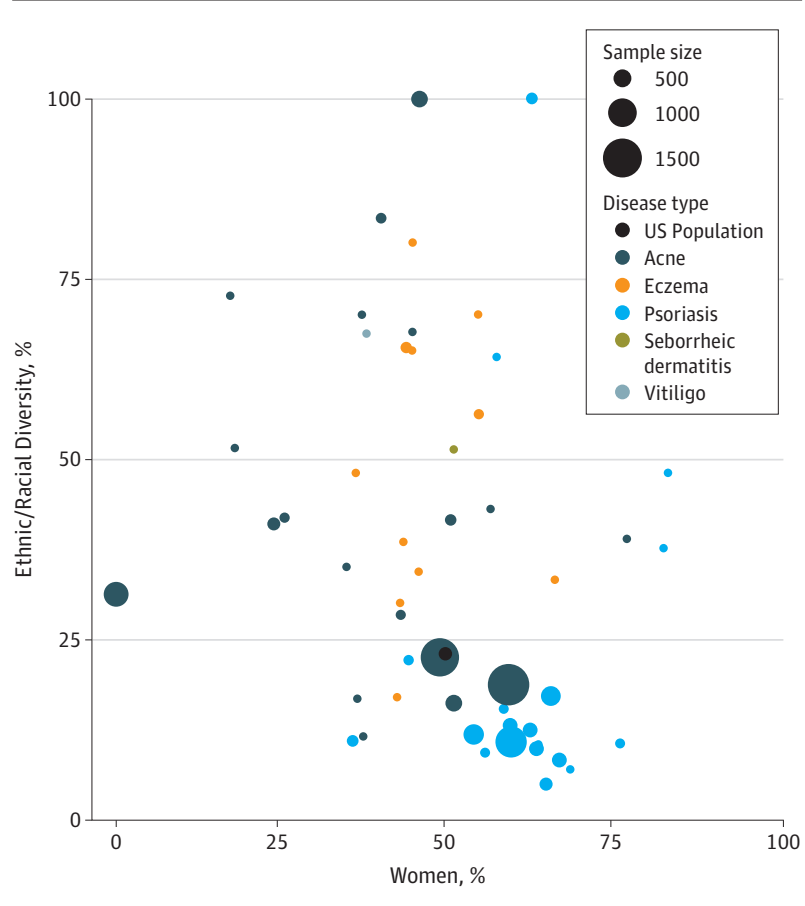

The $x$-axis represents the percentage of women included in each study; $y$-axis, percentage of ethnically/racially diverse individuals in each study. The dot size indicates study population size; dot color represents disease type.

Though US policy may have had an effect on research in the United States, study sponsors and journal editors can help to further encourage and promote the reporting of demographic information. This study demonstrated a statistically significant relationship between journal type, disease type, and funding, and a study's likelihood of reporting its racial/ethnic demographics, suggesting that journals can set policies to encourage demographic reporting and continued demographic diversity.

Establishing racial and ethnic diversity in dermatology RCTs is the first step toward developing systems of investigation that provide insight into the efficacy and side effect profiles of medications across an increasingly diverse population. Race is a societal construct that is often an inadequate proxy for a study participant's genetics. ${ }^{20-22}$ While diverse research cohorts have elucidated differences in human leukocyte antigen-typing that mediate Stevens-Johnson syndrome, ${ }^{23}$ genetic variation in response to antiretroviral medication, ${ }^{24}$ and variability in prevalence of drugtargeted tumor markers, ${ }^{25}$ these findings were ultimately based on the genetic diversity of a racially and ethnically diverse study cohort. Racial and perhaps to a greater extent, ethnic diversity in research will continue to be critical for ensuring all individuals have access to new treatment. However, a focus on characterizing and promoting genetic variability among study participants is required for determining biological differences in drug response and metabolism.

Our findings must be interpreted in the context of the study design. We chose to analyze specific disease states as opposed to including all dermatologic conditions across the literature. In limiting our study to specific conditions, we did not include studies of less common diseases. Common diseases that lack a strong racial propensity and are studied readily in the literature were selected. However, some variation in patient population may be explained by baseline differences in prevalence of these diseases between various races and ethnicities.

The categorization of ethnically Hispanic study participants differed across articles. Some articles characterized Hispanic individuals as ethnically Hispanic and others characterized them as racially Hispanic. In our analysis all Hispanic participants were considered ethnically Hispanic, and cohorts that were either racially or ethnically diverse were classified as diverse. Although this characterization is not ideal, most papers did not include specific racial information on Hispanic study participants, and our study is limited in its ability to fully classify the diversity of such participants and their respective cohorts. Because we cannot consistently subclassify patients of Hispanic ethnicity by race (eg, white, black), our study may be more likely to characterize a study's cohort as diverse. The dearth of data on study participant ethnicity reinforces the need for more detailed reporting of race and ethnicity within the dermatologic.

\section{Conclusions}

Dermatology is a field uniquely positioned to focus its attention on diversity within clinical practice and research. This study demonstrates that while dermatology researchers recruit diverse participant cohorts, our ability to fully understand the composition of patients in dermatology clinical trials is limited by the number of studies that fail to report the racial and ethnic demographics of their participants. Moreover, there is still work to be done in characterizing ethnicity with respect to Hispanic participants. Journals and funding sources can reinforce our diverse clinical trial population by continuing to prioritize racial, ethnic, and genetic diversity within the articles they fund and publish; requiring reporting of racial and ethnic data in all dermatology RCTs will lead us even further. These combined efforts will enable dermatology to be an example within medicine for how to best achieve diversity within research and, by extension, clinical practice.
ARTICLE INFORMATION

Accepted for Publication: July 14, 2016.

Published Online: January 4, 2017. doi:10.1001/jamadermatol.2016.4129

Author Contributions: Drs Charrow and Mostaghimi, had full access to all of the data in the study and take responsibility for the integrity of the data and the accuracy of the data analysis. Concept and design: Charrow, Mostaghimi.
Acquisition, analysis, or interpretation of data: All Authors.

Drafting of the manuscript: Charrow, Mostaghimi Critical revision of the manuscript for important intellectual content: All Authors. Statistical analysis: Charrow, Joyce. Administrative, technical, or material support: Charrow, Mostaghimi.

Study supervision: Charrow, Mostaghimi.

Conflict of Interest Disclosure: None reported.

\section{REFERENCES}

1. Colby S, Ortman J. Projections of the Size and Composition of the US Population: 2014 to 2060. US Department of Commerce. US Census Bureau. https://www.census.gov/content/dam/Census /library/publications/2015/demo/p25-1143.pdf. Accessed December 1, 2015.

2. Geller SE, Adams MG, Carnes M. Adherence to federal guidelines for reporting of sex and 
race/ethnicity in clinical trials. J Womens Health (Larchmt). 2006;15(10):1123-1131.

3. Rochon PA, Mashari A, Cohen A, et al. The inclusion of minority groups in clinical trials: problems of under representation and under reporting of data. Account Res. 2004;11(3-4):215-223.

4. Murthy VH, Krumholz HM, Gross CP.

Participation in cancer clinical trials: race-, sex-, and age-based disparities. JAMA. 2004;291(22):27202726.

5. Burchard EG, Oh SS, Foreman MG, Celedón JC Moving toward true inclusion of racial/ethnic minorities in federally funded studies: a key step for achieving respiratory health equality in the United States. Am J Respir Crit Care Med. 2015;191(5):514-521.

6. Hoel AW, Kayssi A, Brahmanandam S, Belkin M, Conte MS, Nguyen LL. Under-representation of women and ethnic minorities in vascular surgery randomized controlled trials. J Vasc Surg. 2009;50 (2):349-354.

7. Somerson JS, Bhandari M, Vaughan CT, Smith CS, Zelle BA. Lack of diversity in orthopaedic trials conducted in the United States. J Bone Joint Surg Am 2014:96(7):e56.

8. Rochon PA, Mashari A, Cohen A, et al. The inclusion of minority groups in clinical trials: problems of under representation and under reporting of data. Account Res. 2004;11(3-4):215-223.

9. Reardon S. US Tailored-medicine project aims for ethnic balance. Nature. http://www.nature.com /news/us-tailored-medicine-project-aims-for -ethnic-balance-1.18023?WT.mc id=TWT _NatureNews. Accessed August 26, 2015.

10. US Department of Health and Human Services. Guidance for Industry: Collection of Race and
Ethnicity Data in Clinical Trials. http://www.fda.gov /downloads/regulatoryinformation/guidances /ucm126396.pdf. Accessed August 27, 2015

11. Public Law 103-43. National Institutes of Health Revitalization Act of 1993. GovTrack. https://www .govtrack.us/congress/bills/103/s1. Accessed September 10, 2015.

12. Hirano SA, Murray SB, Harvey VM. Reporting, representation, and subgroup analysis of race and ethnicity in published clinical trials of atopic dermatitis in the United States between 2000 and 2009. Pediatr Dermatol. 2012;29(6):749-755.

13. Wysong A, Linos E, Hernandez-Boussard T, Arron ST, Gladstone H, Tang JY. Nonmelanoma skin cancer visits and procedure patterns in a nationally representative sample: national ambulatory medical care survey 1995-2007. Dermatol Surg. 2013;39(4):596-602.

14. Harris PA, Taylor R, Thielke R, Payne J, Gonzalez $\mathrm{N}$, Conde JG. Research electronic data capture (REDCap)-a metadata-driven methodology and workflow process for providing translational research informatics support. J Biomed Inform. 2009:42(2):377-381.

15. Geller SE, Adams MG, Carnes M. Adherence to federal guidelines for reporting of sex and race/ethnicity in clinical trials. J Womens Health (Larchmt). 2006;15(10):1123-1131.

16. Rochon PA, Mashari A, Cohen A, et al. The inclusion of minority groups in clinical trials: problems of under representation and under reporting of data. Account Res. 2004;11(3-4):215-223.

17. Oh SS, Galanter J, Thakur N, et al. Diversity in Clinical and Biomedical Research: A promise yet to be fulfilled. PLoS Med. 2015;12(12):e1001918.
18. US Congress. National Institutes of Health Revitalization Act of DC. Act to Amend the Public Health Service Act to Revise and Extend the Programs of the National Institutes of Health, and for Other Purposes. Public Law Washington; Washington, DC 1993:103-143.

19. National Institutes of Health. NIH Guideline on the Inclusion of Women and Minorities as Subjects in Clinical Research-Amended October 2000. https://grants.nih.gov/grants/funding/women_min /guidelines amended 10 2001.htm. Accessed November 3, 2016.

20. Serre D, Pääbo S. Evidence for gradients of human genetic diversity within and among continents. Genome Res. 2004;14(9):1679-1685.

21. Ng PC, Zhao Q, Levy S, Strausberg RL, Venter JC. Individual genomes instead of race for personalized medicine. Clin Pharmacol Ther. 2008 84(3):306-309.

22. Yudell M, Roberts D, DeSalle R, Tishkoff S. Science and society: taking race out of human genetics. Science. 2016;351(6273):564-565.

23. Chung $\mathrm{WH}$, Hung $\mathrm{SI}$, Hong $\mathrm{HS}$, et al. Medical genetics: a marker for Stevens-Johnson syndrome. Nature. 2004:428(6982):486.

24. Frasco MA, Mack WJ, Van Den Berg D, et al. Underlying genetic structure impacts the association between CYP2B6 polymorphisms and response to efavirenz and nevirapine. AIDS. 2012; 26(16):2097-2106.

25. Fejerman L, Ahmadiyeh N, Hu D, et al: COLUMBUS Consortium. Genome-wide association study of breast cancer in Latinas identifies novel protective variants on 6q25. Nat Commun. 2014;5: 5260. 